\title{
Tandem Cu-catalyzed ketenimine formation and intramolecular nucleophile capture: Synthesis of 1,2-dihydro-2-iminoquinolines from 1-(o-acetamidophenyl)propargyl alcohols
}

\author{
Gadi Ranjith Kumar ${ }^{\ddagger 1,2}$, Yalla Kiran Kumar ${ }^{\ddagger 2}$, Ruchir Kant ${ }^{3}$
}

and Maddi Sridhar Reddy ${ }^{*} 1,2, \S$

\author{
Full Research Paper \\ Address: \\ ${ }^{1}$ Medicinal \& Process Chemistry Division, CSIR-Central Drug \\ Research Institute, BS-10/1, Sector 10, Jankipuram extension, \\ Sitapur Road, P.O. Box 173, Lucknow 226031, India, ${ }^{2}$ Academy of \\ Scientific and Innovative Research, New Delhi 110001, India and \\ ${ }^{3}$ Molecular \& Structural Biology Division, CSIR-Central Drug \\ Research Institute,BS-10/1, Sector 10, Jankipuram extension, Sitapur \\ Road, P.O. Box 173, Lucknow 226031, India \\ Email: \\ Maddi Sridhar Reddy - msreddy@cdri.res.in \\ * Corresponding author $\ddagger$ Equal contributors \\ $\S \mathrm{Tel}+91-7897582222$. \\ Keywords: \\ alkyne; azide; cycloaddition; cyclization; quinoline \\ Beilstein J. Org. Chem. 2014, 10, 1255-1260. \\ doi:10.3762/bjoc. 10.125 \\ Received: 12 February 2014 \\ Accepted: 30 April 2014 \\ Published: 28 May 2014 \\ Associate Editor: J. P. Wolfe \\ (c) 2014 Kumar et al; licensee Beilstein-Institut. \\ License and terms: see end of document.
}

\begin{abstract}
The copper-catalyzed ketenimine formation reaction of 1-(o-acetamidophenyl)propargyl alcohols with various sulfonyl azides is found to undergo a concomitant intramolecular nucleophile attack to generate 1,2-dihydro-2-iminoquinolines after aromatization (via elimination of acetyl and hydroxy groups) and tautomerization. The reaction produces 4-substituted and 3,4-unsubstituted title compounds in moderate to good yields under mild reaction conditions.
\end{abstract}

\section{Introduction}

The synthesis of $N$-sulfonylketenimines via CuAAC (coppercatalyzed azide-alkyne cycloaddition) between terminal alkynes and sulfonyl azides has staged for a conceptually novel class of approaches for the synthesis of various nitrogen-containing cyclic and acyclic motifs of pharmaceutical and material interests [1-23]. After its discovery by Chang and co-workers [1-6], various groups (including the discoverers) have utilized the reaction for the synthesis of diverse chemical compounds by trapping the thus formed ketenimine inter- and intramolecularly. Various multicomponent reactions using external nucleophiles like $\mathrm{H}_{2} \mathrm{O}$, alcohols, amines, imines, etc., have been reported while very few recent methods [16-23], including ours [16], disclosed the utilization of internal nucleophiles for trapping the ketenimines successfully. In continuation of our interest in the 
functionalization of alkynes through electrophilic activation [24-29], we herein report a synthesis of 1,2-dihydro-2-iminoquinolines (tauromerized form of 2-sulfonylaminoquinolines) from 1-(o-acetamidophenyl)propargyl alcohols via coppercatalyzed ketenimine formation with various sulfonyl azides.

2-Aminoquinolines and their derivatives have been found to be important constituents in pharmaceutical chemistry [30-42] and also found to play a crucial role in molecular recognition processes [43-46]. Due to its vast-spread importance, several methods have been developed to construct this useful framework. Apart from the classical Chichibabin reaction [47], there has been considerable interest shown for the synthesis of these compounds with varying substitution patterns [48-64]. Most of the methods used presynthesized quinolines for the 2-amination via either creating initially a leaving group and its subsequent substitution or via activation of the nitrogen atom and direct amination at C-2 while few methods afforded the direct 2 -aminoquinoline synthesis from the acyclic precursors.

Most recently, we have disclosed a method for the synthesis of $E$ - $\alpha, \beta$-unsaturated amides from propargyl acetates via copper catalyzed ketenimine formation with sulfonyl azides (Scheme 1) [16]. The reaction was thought to proceed through intramolecular nucleophilic attack on the in situ generated ketenimine. We became curious to know the fate of the reaction in the presence of another internal nucleophile in the same distance (6-membered) as a competitor.

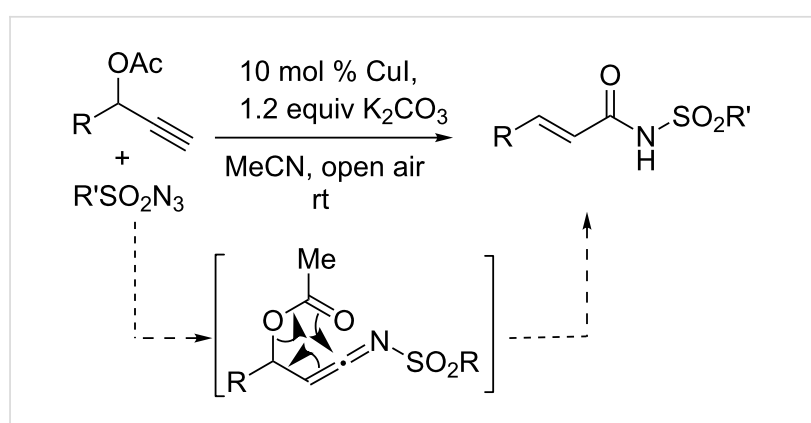

Scheme 1: Synthesis of unsaturated amides via ketenimine formation.

\section{Results and Discussion}

Thus, we synthesized a substrate $\mathbf{3}$ (from $\mathbf{1}$ via 2a) through Grignard reaction followed by acetylation (Scheme 2). Substrate 3 contains two nucleophiles in the form of acetyl and acetamide groups at equal distance. When we treated 3 with similar reaction conditions $\left(\mathrm{TsN}_{3}, 10 \mathrm{~mol} \% \mathrm{CuI}, 1.2\right.$ equiv $\mathrm{K}_{2} \mathrm{CO}_{3}, 0.1 \mathrm{M} \mathrm{CH}_{3} \mathrm{CN}$ ) as used in the previous method, surprisingly, only $\alpha, \beta$-unsaturated amide $\mathbf{5}$ was obtained as a single product through acetyl migration on the intermediate 4 . No trace of product through acetamide attack was obtained, which was probably due to the weaker nucleophilic nature of the latter nucleophile. We then wanted to test the method on $2 \mathbf{a}$ which contains a hydroxy group as a nucleophile for a relatively strained 4-membered attack and the acetamide group for the 6-membered attack. In our earlier study, the hydroxy group was found to be a less effective nucleophile compared to the acetyl

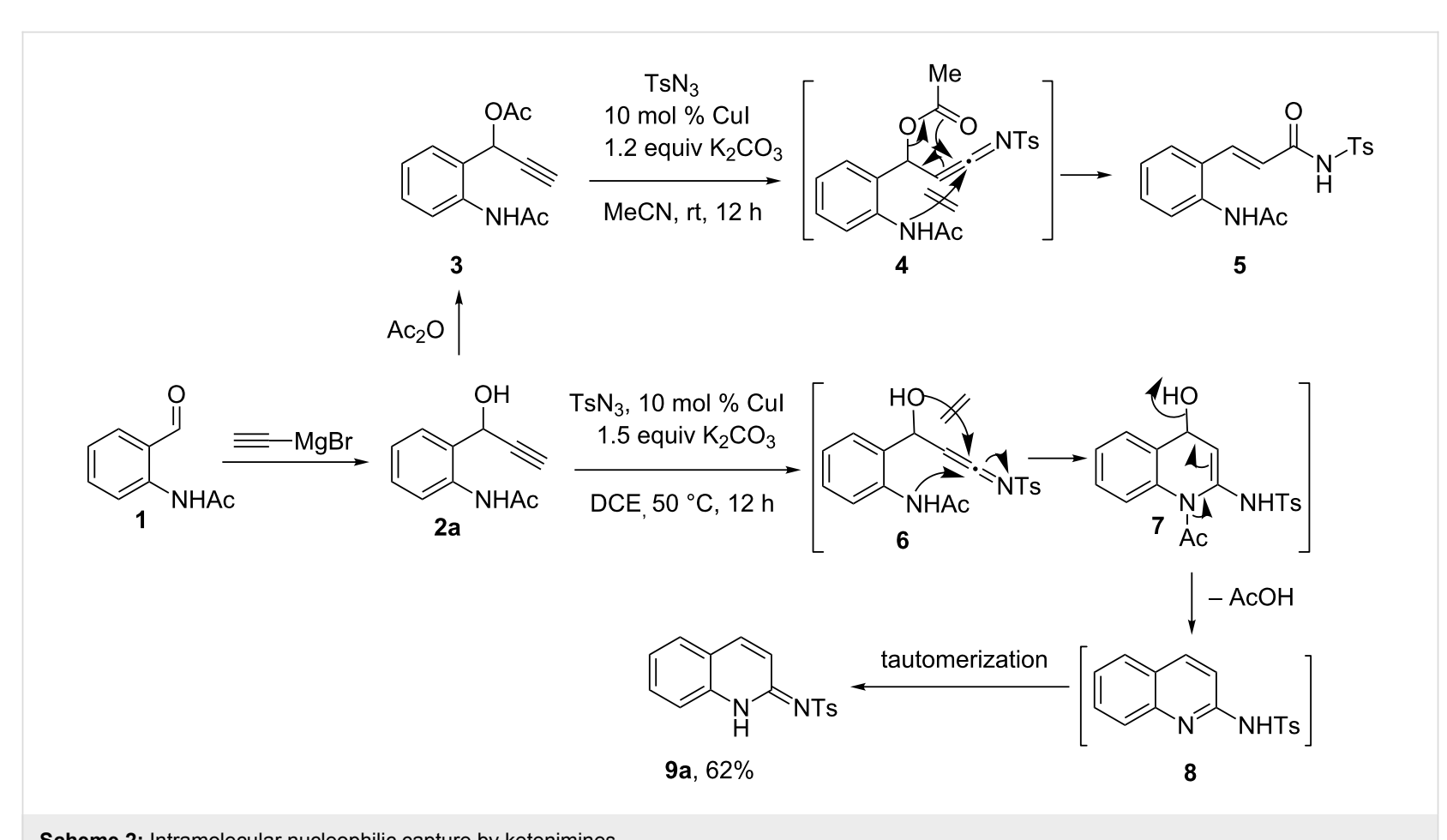


group in such a reaction, as the earlier requires higher energy for its strained 4-membered cyclization. In light of this, we speculated that the acetamide group might have more chances for the cyclization in the tentative intermediate $\mathbf{6}$. As expected, the reaction on 2a proceeded through a 6-membered cyclization to form 7 which underwent aromatization via elimination of acetic acid to produce $\mathbf{8}$. Product $\mathbf{8}$ exists in tautomerized form of $\mathbf{9}$ (vide infra, X-ray structure of $\mathbf{9 j}$ ). In fact, an elegant synthesis of such compounds was earlier achieved by Wang et al. through three component coupling reaction under similar conditions [13]. The method was shown to be not working for the synthesis of 4-unsubstituted adducts as the 2-aminobenzaldehyde was found to be unreactive in the given conditions and, moreover, the reaction is not possible with acetylene as the alkyne partner to produce 3,4-unsubstituted adducts. We herein report the intramolecular version of Wang's protocol for the synthesis of differently substituted products.

To explore the practicality of the above reaction, a series of starting materials were selected with the variation in substitution on propargyl alcohols as well as sulfonyl azides. It was found that the cascade process was applicable for a wide range of substrates providing the dihydroquinoline derivatives 9 in yields ranging from $36 \%$ to $77 \%$ (Scheme 3 ). Initially, we screened 2-propargyl alcohols prepared from aminobenzaldehydes as they were unreactive in Wang's protocol. Thus, 2a was treated with various sulfonyl azides. Trifluoromethanesulfonyl azides reacted similar to toluenesulfonyl azide to afford the<smiles>[R]C(=O)c1ccccc1NC(C)=O</smiles><smiles></smiles>

9a, $62 \%$<smiles>O=S(=O)(/N=c1\ccc2ccccc2[nH]1)c1ccc(C(F)(F)F)cc1</smiles><smiles>O=S(=O)(/N=c1\ccc2ccccc2[nH]1)c1ccccc1C(F)(F)F</smiles><smiles>O=S(=O)(/N=c1\ccc2ccccc2[nH]1)c1ccccc1</smiles>
9d, $46 \%$<smiles>CS(=O)(=O)/N=c1\ccc2ccccc2[nH]1</smiles>

$9 e, 36 \%$<smiles>Fc1ccc2ccc(=N[As])[nH]c2c1</smiles>
9f, $49 \%$<smiles>O=S(=O)(N=c1ccc2ccc(F)cc2[nH]1)c1ccc(C(F)(F)F)cc1</smiles><smiles>O=S(=O)(/N=c1\ccc2ccc(F)cc2[nH]1)c1ccccc1C(F)(F)F</smiles>

9h, $48 \%$<smiles>O=S(=O)(N=c1ccc2ccc(F)cc2[nH]1)c1ccccc1</smiles><smiles>Cc1c/c(=N\[Te])[nH]c2ccccc12</smiles><smiles>Cc1c/c(=N/S(=O)(=O)c2ccccc2)[nH]c2ccccc12</smiles><smiles>C[N+](=O)/C=C1\C=C([N+](C)=O)c2ccccc2N1</smiles><smiles>CCc1c/c(=N\[Al-])[nH]c2ccccc12</smiles><smiles>[134Sn]</smiles>

9j, $77 \%$ 9k, $58 \%$ 9I, $48 \%$

9m, $58 \%$<smiles>[3H]N=c1cc(CCC)c2ccccc2[nH]1</smiles>

9n, $61 \%$<smiles>Clc1ccc2[nH]c(=N[AsH3-])cc(-c3ccccc3)c2c1</smiles>

9s, $55 \%$<smiles>Cc1ccc2[nH]/c(=N/[AsH])cc(C(C)C)c2c1</smiles>

9o, $67 \%$<smiles>[As]N=c1cc(-c2ccccc2)c2ccccc2[nH]1</smiles>

$9 p, 61 \%$<smiles>[3H]N=c1cc(-c2ccc(F)cc2)c2cc(C)ccc2[nH]1</smiles>

9t, $60 \%$<smiles>COc1ccc(-c2c/c(=N\[Te])[nH]c3ccccc23)cc1</smiles>

$9 u, 65 \%$<smiles>Cc1ccc2c(-c3ccccc3)c/c(=N\[As])[nH]c2c1</smiles>

9r, $69 \%$<smiles>[N-]=c1cc(-c2ccccc2)c2cc([N+](=O)[O-])ccc2[nH]1</smiles>

$9 v, 0 \%$ 
products $9 \mathbf{b}$ and $9 \mathbf{c}$ in $71 \%$ and 55\% yields. The lower yield in case of $9 \mathbf{c}$ can be attributed to the steric hindrance created by the bulky triflruoromethyl group at the ortho position. Benzeneand methanesulfonyl azides produced the corresponding products (9d and 9e) in somewhat lower yields (46\% and 36\%, respectively). Fluorinated $2^{\circ}$-propargyl alcohol $\mathbf{2 b}$ was then reacted with various aryl sulfonyl azides to get the corresponding products $9 \mathbf{f}-\mathbf{i}$ in yields ranging from $45-50 \%$.

Next, $3^{\circ}$-propargyl alcohols prepared from aminoacetophenones and aminobenzophenones were subjected to the title reaction for the synthesis of 4-methyl/phenyl-1,2-dihydro-2-iminoquinolines. It was found that these $3^{\mathrm{o}}$-propargyl alcohols were more productive compared to the above $2^{\circ}$-propargyl alcohols. Thus $\mathbf{2 c - f}$ were subjected to the standard reaction conditions with various sulfonyl azides to get the corresponding 4-alkylsubstituted quinoline derivatives $\mathbf{9 j - 0}$ in $48-77 \%$ yields. In further exploration, 4-phenyl-substituted adducts $\mathbf{9 p}$ and $\mathbf{9 q}$ were synthesized from $\mathbf{2 g}$ and $\mathbf{2 h}$ in $61 \%$ and $72 \%$ yields, respectively. Halogen groups (chloro and fluoro) on the core part as well as the pendant phenyl ring survived well in the reaction to produce the products $(9 \mathbf{r}-\mathbf{t})$ in yields ranging from $55 \%$ to $69 \%$. Electron rich phenyl substrate 21 produced the corresponding product $9 u$ in $65 \%$ yield while electron poor substrate $\mathbf{2 m}$ was found to be unreactive in the reaction.

The structures of the products were confirmed by ${ }^{1} \mathrm{H}$ NMR, ${ }^{13} \mathrm{C}$ NMR and High Resolution Mass Spectrometry (HRMS). X-ray crystallography of one of the compounds, $9 \mathbf{j}$, gave unambiguous structure confirmation (Figure 1). See also Supporting Information File 1, pages S49-S57 and Supporting Information File 2.

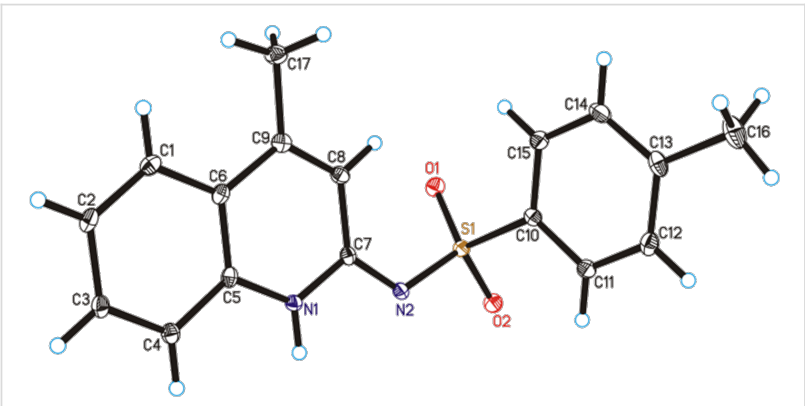

Figure 1: X-ray Structure of 9j (CCDC number 971729).

\section{Conclusion}

We have described a method for the synthesis of 1,2-dihydro-2iminoquinolines, tautomerized products of 2-tosylaminoquinolines, from 1-(o-acetamidophenyl)propargyl alcohols through copper-catalyzed ketenimine formation with various sulfonyl azides and concomitant intramolecular nucleophilic attack. The method is overall an intramolecular version of the Wang's protocol for the synthesis of differently substituted 1,2-dihydro2-tosyliminoquinolines which cannot be synthesized by the latter method. The reaction was performed under mild conditions to obtain the products in good yields and with a broad spectrum of substitution patterns.

\section{Experimental}

General information: All reagents and solvents were purchased from commercial sources and used without purification. NMR spectra were recorded with a 300 or $400 \mathrm{MHz}$ spectrometer for ${ }^{1} \mathrm{H}$ NMR, 75 or $100 \mathrm{MHz}$ for ${ }^{13} \mathrm{C}$ NMR spectroscopy. Chemical shifts are reported relative to tetramethylsilane in $\mathrm{CDCl}_{3}$ or to residual signals of undeuterasted solvent $\mathrm{CDCl}_{3} / \mathrm{DMSO}-d_{6}$ for ${ }^{1} \mathrm{H}$ and ${ }^{13} \mathrm{C}$ NMR spectroscopy. Multiplicities are reported as follows: singlet (s), doublet (d), broad singlet (bs), doublet of doublets (dd), doublet of triplets (dt), triplet (t), quartet (q), multiplet $(\mathrm{m})$. HRMS spectra were recorded by using a QTof mass spectrometer. Column chromatography was performed with silica gel (100-200 mesh) as the stationary phase. All reactions were monitored by using TLC. The purity and characterization of compounds were further established by using HRMS.

General procedure for the synthesis of 9 from 2 taking synthesis of 9a as an example: To the substrate 2a (190 mg, $1 \mathrm{mmol})$ dissolved in dichloroethane $(5 \mathrm{~mL})$ was added tosyl azide (236 mg, $1.2 \mathrm{mmol}$ ), copper iodide (19 mg, $0.1 \mathrm{mmol}$ ), and $\mathrm{K}_{2} \mathrm{CO}_{3}(207 \mathrm{mg}, 1.5 \mathrm{mmol})$. The mixture was stirred at 50 ${ }^{\circ} \mathrm{C}$ for $12 \mathrm{~h}$. The reaction mixture was then added water $(5 \mathrm{~mL})$ followed by brine solution $(5 \mathrm{~mL})$ and extracted with ethyl acetate $(3 \times 10 \mathrm{~mL})$. The combined extracts were dried over $\mathrm{Na}_{2} \mathrm{SO}_{4}$, filtered and concentrated. The crude solid product was purified by column chromatography (silicagel, 20-30\% EtOAc in hexanes) to get the pure product 9 (180 $\mathrm{mg}, 62 \%$ yield).

\section{Supporting Information}

\section{Supporting Information File 1}

Analytical data.

[http://www.beilstein-journals.org/bjoc/content/ supplementary/1860-5397-10-125-S1.pdf]

\section{Supporting Information File 2}

$\mathrm{X}$-ray structure.

[http://www.beilstein-journals.org/bjoc/content/ supplementary/1860-5397-10-125-S2.cif]

\section{Acknowledgements}

GRK and YKK thank CSIR for the PhD fellowships. We thank SAIF division CSIR-CDRI for the analytical support. We thank 
Dr. Tejender S. Thakur of Molecular and Structural Biology Division, CSIR-Central Drug Research Institute for supervising the X-ray data collection and structure determination of $\mathbf{9} \mathbf{j}$ reported in this paper. We gratefully acknowledge the financial support by CSIR-Network project 'BSC0102' (CSIR-CDRITHUNDER) and by DST under the 'Fast Track Proposal Scheme for Young Scientists'. CDRI Communication No. 8678.

\section{References}

1. Kim, S. H.; Park, S. H.; Choi, J. H.; Chang, S. Chem.-Asian J. 2011, 6, 2618-2634. doi:10.1002/asia.201100340

2. Yoo, E. J.; Chang, S. Curr. Org. Chem. 2009, 13, 1766-1776. doi:10.2174/138527209789630497

3. Yoo, E. J.; Park, S. H.; Lee, S. H.; Chang, S. Org. Lett. 2009, 11, 1155-1158. doi:10.1021/ol900023t

4. Cho, S. H.; Chang, S. Angew. Chem., Int. Ed. 2007, 46, 1897-1900. doi:10.1002/anie.200604358

5. Kim, J.; Lee, S. Y.; Lee, J.; Do, Y.; Chang, S. J. Org. Chem. 2008, 73, 9454-9457. doi:10.1021/jo802014g

6. Bae, I.; Han, H.; Chang, S. J. Am. Chem. Soc. 2005, 127, 2038-2039. doi:10.1021/ja0432968

7. Sun, L.; Zhu, Y.; Lu, P.; Wang, Y. Org. Lett. 2013, 15, 5894-5897. doi:10.1021/ol402996x

8. Xing, Y.; Zhao, H.; Shang, Q.; Wang, J.; Lu, P.; Wang, Y. Org. Lett. 2013, 15, 2668-2671. doi:10.1021/ol4010323

9. Zhou, F.; Liu, X.; Zhang, N.; Liang, Y.; Zhang, R.; Xin, X.; Dong, D. Org. Lett. 2013, 15, 5786-5789. doi:10.1021/ol4028368

10. Jiang, Z.; Lu, P.; Wang, Y. Org. Lett. 2012, 14, 6266-6269. doi:10.1021/ol303023y

11. Lu, P.; Wang, Y. Chem. Soc. Rev. 2012, 41, 5687-5705. doi:10.1039/c2cs35159e

12. Lu, P.; Wang, Y. Synlett 2010, 165-173. doi:10.1055/s-0029-1218558

13. Cui, S.-L.; Wang, J.; Wang, Y.-G. Tetrahedron 2008, 64, 487-495. doi:10.1016/j.tet.2007.11.025

14. Yao, W.; Pan, L.; Zhang, Y.; Wang, G.; Wang, X.; Ma, C. Angew. Chem., Int. Ed. 2010, 49, 9210-9214. doi:10.1002/anie.201004685

15. Cassidy, M. P.; Raushel, J.; Fokin, V. V. Angew. Chem., Int. Ed. 2006, 45, 3154-3157. doi:10.1002/anie.200503805

16. Kumar, Y. K.; Kumar, G. R.; Reddy, M. S. J. Org. Chem. 2014, 79, 823-828. doi:10.1021/j0402570t

17. Chauhan, D. P.; Varma, S. J.; Vijeta, A.; Banerjee, P.; Talukdar, P. Chem. Commun. 2014, 50, 323-325. doi:10.1039/c3cc47182a

18. Wang, J.; Wang, J.; Lu, P.; Wang, Y. J. Org. Chem. 2013, 78 , 8816-8820. doi:10.1021/jo401094j

19. Cheng, G.; Cui, X. Org. Lett. 2013, 15, 1480-1483. doi:10.1021/ol400219n

20. Nagaraj, M.; Boominathan, M.; Perumal, D.; Muthusubramanian, S.; Bhuvanesh, N. J. Org. Chem. 2012, 77, 6319-6326. doi:10.1021/jo300855f

21. Li, S.; Luo, Y.; Wu, J. Org. Lett. 2011, 13, 3190-3193. doi:10.1021/ol2011067

22. Yoo, E. J.; Chang, S. Org. Lett. 2008, 10, 1163-1166. doi:10.1021/ol800049b

23. Chen, Z.; Zheng, D.; Wu, J. Org. Lett. 2011, 13, 848-851. doi:10.1021/ol102775s

24. Reddy, M. S.; Thirupathi, N.; Babu, M. H.; Puri, S. J. Org. Chem. 2013, 78, 5878-5888. doi:10.1021/jo400499r
25. Reddy, M. S.; Kumar, Y. K.; Thirupathi, N. Org. Lett. 2012, 14, 824-827. doi:10.1021/ol2033493

26. Reddy, M. S.; Thirupathi, N.; Babu, M. H. Eur. J. Org. Chem. 2012, 5803-5809. doi:10.1002/ejoc.201200782

27. Reddy, M. S.; Thirupathi, N.; Kumar, Y. K. RSC Adv. 2012, 2, 3986-3992. doi:10.1039/c2ra20213a

28. Ravindar, K.; Reddy, M. S.; Deslongchamps, P. Org. Lett. 2011, 13, 3178-3181. doi:10.1021/ol201102x

29. Reddy, M. S.; Thirupathi, N.; Haribabu, M. Beilstein J. Org. Chem. 2013, 9, 180-184. doi:10.3762/bjoc.9.21

30. Cheng, Y.; Judd, T. C.; Bartberger, M. D.; Brown, J.; Chen, K.; Fremeau, R. T., Jr.; Hickman, D.; Hitchcock, S. A.; Jordan, B.; Li, V.; Lopez, P.; Louie, S. W.; Luo, Y.; Michelsen, K.; Nixey, T.; Powers, T. S.; Rattan, C.; Sickmier, E. A.; St. Jean, D. J.; Wahl, R. C., Jr.; Wen, P. H.; Wood, S. J. Med. Chem. 2011, 54 , 5836-5857. doi:10.1021/jm200544q

31. Inglis, S.; Jones, R.; Fritz, D.; Stojkoski, C.; Booker, G.; Pyke, S. Org. Biomol. Chem. 2005, 3, 2543-2557. doi:10.1039/b504498g

32. Gerster, J. F.; Lindstrom, K. J.; Miller, R. L.; Tomai, M. A.; Birmachu, W.; Bomersine, S. N.; Gibson, S. J.; Imbertson, L. M.; Jacobson, J. R.; Knafla, R. T.; Maye, P. V.; Nikolaides, N.; Oneyemi, F. Y.; Parkhurst, G. J.; Pecore, S. E.; Reiter, M. J.; Scribner, L. S.; Testerman, T. L.; Thompson, N. J.; Wagner, T. L.; Weeks, C. E.; Andre, J.-D.; Lagain, D.; Bastard, Y.; Lupu, M. J. Med. Chem. 2005, 48, 3481-3491. doi:10.1021/jm049211v

33. Inglis, S. R.; Stojkoski, C.; Branson, K. M.; Cawthray, J. F.; Fritz, D.; Wiadrowski, E.; Pyke, S. M.; Booker, G. W. J. Med. Chem. 2004, 47, 5405-5417. doi:10.1021/jm049533z

34. Tavares, F. X.; Boncek, V.; Deaton, D. N.; Hassell, A. M.; Long, S. T.; Miller, A. B.; Payne, A. A.; Miller, L. R.; Shewchuk, L. M.; Wells-Knecht, K.; Willard, D. H., Jr.; Wright, L. L.; Zhou, H.-Q. J. Med. Chem. 2004, 47, 588-599. doi:10.1021/jm030373।

35. Webb, T. R.; Lvovskiy, D.; Kim, S.-A.; Ji, X.-d.; Melman, N.; Linden, J.; Jacobson, K. A. Bioorg. Med. Chem. 2003, 11, 77-85. doi:10.1016/S0968-0896(02)00323-1

36. Renau, T. E.; Léger, R.; Yen, R.; She, M. W.; Flamme, E. M.; Sangalang, J.; Gannon, C. L.; Chamberland, S.; Lomovskaya, O.; Lee, V. J. Bioorg. Med. Chem. Lett. 2002, 12, 763-766. doi:10.1016/S0960-894X(02)00006-9

37. Brzozowski, Z.; Saçzewski, F. J. Med. Chem. 2002, 45, 430-437. doi:10.1021/jm010953n

38. Selwood, D. L.; Brummell, D. G.; Glen, R. C.; Goggin, M. C.; Reynolds, K.; Tatlock, M. A.; Wishart, G. Bioorg. Med. Chem. Lett. 2001, 11, 1089-1092. doi:10.1016/S0960-894X(01)00141-X

39. Colotta, V.; Catarzi, D.; Varano, F.; Cecchi, L.; Filacchioni, G.; Martini, C.; Trincavelli, L.; Lucacchini, A. J. Med. Chem. 2000, 43, 3118-3124. doi:10.1021/jm000936i

40. Pfister, J. R. J. Nat. Prod. 1988, 51, 969-970. doi:10.1021/np50059a027

41. Campbell, S. F.; Hardstone, J. D.; Palmer, M. J. J. Med. Chem. 1988, 31, 1031-1035. doi:10.1021/jm00400a025

42. Alhaider, A. A.; Abdelkader, M. A.; Lien, E. J. J. Med. Chem. 1985, 28, 1394-1398. doi:10.1021/jm00148a004

43. Li, J.-S.; Gold, B. J. Org. Chem. 2005, 70, 8764-8771. doi:10.1021/jo0511445

44. Li, J.-S.; Chen, F.-X.; Shikiya, R.; Marky, L. A.; Gold, B. J. Am. Chem. Soc. 2005, 127, 12657-12665. doi:10.1021/ja0530218 45. Nakatani, K.; Sando, S.; Kumasawa, H.; Kikuchi, J.; Saito, I. J. Am. Chem. Soc. 2001, 123, 12650-12657. doi:10.1021/ja0109186 
46. Nakatani, K.; Sando, S.; Saito, I. J. Am. Chem. Soc. 2000, 122, 2172-2177. doi:10.1021/ja992956j

47. Mcgill, C. K.; Rappa, A. Adv. Heterocycl. Chem. 1988, 44, 1-79. doi:10.1016/S0065-2725(08)60261-5

48. Li, G.; Jia, C.; Sun, K. Org. Lett. 2013, 15, 5198-5201. doi:10.1021/ol402324v

49. Liu, B.; Gao, H.; Yu, Y.; Wu, W.; Jiang, H. J. Org. Chem. 2013, 78, 10319-10328. doi:10.1021/jo401707j

50. Tomioka, T.; Takahashi, Y.; Maejima, T. Org. Biomol. Chem. 2012, 10, 5113-5118. doi:10.1039/c2ob25709b

51. Shelar, D. P.; Birari, D. R.; Rote, R. V.; Patil, S. R.; Toche, R. B.; Jachak, M. N. J. Phys. Org. Chem. 2011, 24, 203-211. doi:10.1002/poc. 1727

52. Yin, J.; Xiang, B.; Huffman, M. A.; Raab, C. E.; Davies, I. W. J. Org. Chem. 2007, 72, 4554-4557. doi:10.1021/jo070189y

53. Couturier, M.; Caron, L.; Tumidajski, S.; Jones, K.; White, T. D. Org. Lett. 2006, 8, 1929-1932. doi:10.1021/ol060473w

54. Arienzo, R.; Clark, D. E.; Cramp, S.; Daly, S.; Dyke, H. J.; Lockey, P.; Norman, D.; Roach, A. G.; Stuttle, K.; Tomlinson, M.; Wong, M.; Wren, S. P. Bioorg. Med. Chem. Lett. 2004, 14, 4099-4102. doi:10.1016/j.bmcl.2004.05.051

55. Storz, T.; Marti, R.; Meier, R.; Nury, P.; Roeder, M.; Zhang, K. Org. Process Res. Dev. 2004, 8, 663-665. doi:10.1021/op049944p

56. Manley, P. J.; Bilodeau, M. T. Org. Lett. 2002, 4, 3127-3129. doi:10.1021/ol0264556

57. Schmittel, M.; Steffen, J.-P.; Engels, B.; Lennartz, C.; Hanrath, M. Angew. Chem., Int. Ed. 1998, 37, 2371-2373. doi:10.1002/(SICI)1521-3773(19980918)37:17<2371::AID-ANIE2371>3 .0.CO;2-N

58. Zhou, L.; Tu, S.; Shi, D.; Dai, G. J. Chem. Res., Synop. 1998, 398-399. doi:10.1039/A800588E

59. Glennon, R. A.; Slusher, R. M.; Lyon, R. A.; Titeler, M.; McKenney, J. D. J. Med. Chem. 1986, 29, 2375-2380. doi:10.1021/jm00161a038

60. Abramovitch, R. A.; Pilski, J.; Konitz, A.; Tomasik, P. J. Org. Chem. 1983, 48, 4391-4393. doi:10.1021/jo00171a048

61. Kurbatov, Y. V.; Solekhova, M. A. Zh. Org. Khim. 1981, 17, 1121.

62. Abramovich, R. A.; Singer, G. M. J. Org. Chem. 1974, 39, 1795-1802. doi:10.1021/jo00927a001

63. Abramovich, R. A.; Rogers, R. B. J. Org. Chem. 1974, 39, 1802-1807. doi:10.1021/j000927a002

64. Abramovich, R. A.; Singer, G. M. J. Am. Chem. Soc. 1969, 91, 5672-5673. doi:10.1021/ja01048a059

\section{License and Terms}

This is an Open Access article under the terms of the Creative Commons Attribution License

(http://creativecommons.org/licenses/by/2.0), which permits unrestricted use, distribution, and reproduction in any medium, provided the original work is properly cited.

The license is subject to the Beilstein Journal of Organic Chemistry terms and conditions:

(http://www.beilstein-journals.org/bjoc)

The definitive version of this article is the electronic one which can be found at:

doi:10.3762/bjoc. 10.125 